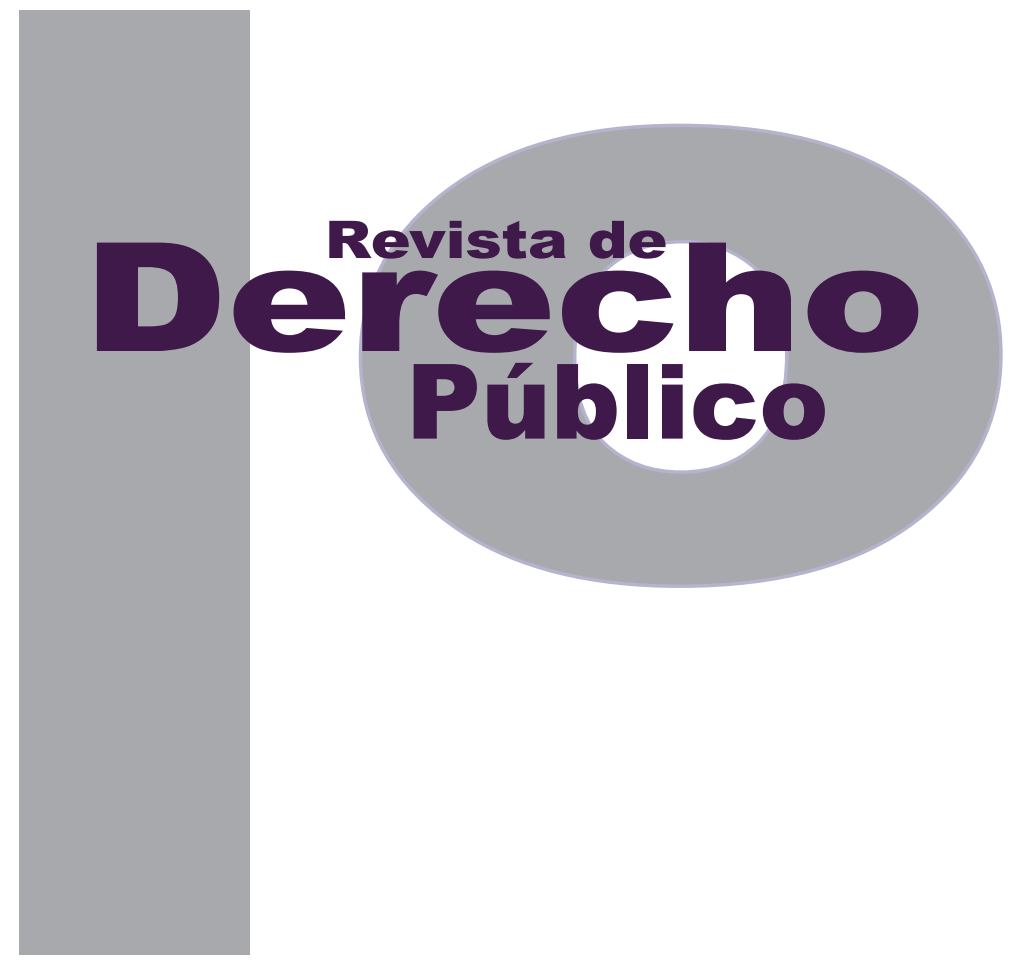

EVOLUCIÓN CONSTITUCIONAL DEL DERECHO A LA PENSIÓN DE SOBREVIVIENTE DE LAS PAREJAS DEL MISMO SEXO: ÁMBITO JURISPRUDENCIAL

Adriana María Buitrago Escobar

MARÍA FERNANDA SUÁREZ TRUJILLO

YANIZA GIRALDO RESTREPO

Artículo de reflexión

DOI: http://dx.doi.org/10.15425/redepub.35.2015.13

Universidad de los Andes

Facultad de Derecho

Rev. derecho publico No.35

julio - diciembre de 2015. ISSN 1909-7778 


\section{Evolución constitucional del derecho a la pensión de sobreviviente de las parejas del mismo sexo: ámbito jurisprudencial}

\section{Resumen}

En Colombia, la Corte Constitucional se ha pronunciado en reiteradas ocasiones respecto del derecho a la pensión de sobreviviente entre las parejas del mismo sexo, señalando que se entiende por pensión de sobreviviente:

Aquel derecho fundamental de carácter cierto, indiscutible e irrenunciable, por estar asociado íntimamente con valores sujetos de tutela, como el derecho a la vida, a la seguridad social, a la salud y al trabajo, condiciones estas que le dan el carácter inalienable, inherente y esencial, dada la indefensión del beneficiario respecto a quien debe reconocerle y pagarle su derecho. (T-173/1994, A. Martínez).

Conforme a lo anterior, este artículo pretende establecer si se está reconociendo el derecho adquirido de pensión de sobreviviente entre las parejas del mismo sexo, desde una perspectiva jurisprudencial. La metodología empleada parte del paradigma histórico-hermenéutico propuesto por Habermas, ya que con él se puede entender el impacto que ha tenido en nuestro país la nueva posibilidad de "familia", con la cual se generan unos derechos y unas obligaciones entre los participantes que serían las personas del mismo sexo, destacando la vulnerabilidad a la que se exponen permanentemente.

El método adoptado es el teórico-dogmático. Se estudia el avance que ha tenido la jurisprudencia en la protección al derecho de pensión de sobreviviente para las parejas del mismo sexo, mediante la interpretación que ha dado la Corte Constitucional colombiana.

Como conclusión general, se evidencia que existe en Colombia un problema de discriminación frente a las parejas del mismo sexo, que incluye la vulneración de derechos de todo tipo, y que transgrede los derechos fundamentales, especialmente el derecho a la igualdad.

Palabras clave: pensión de sobreviviente, homosexual, jurisprudencia, igualdad, derechos fundamentales, Constitución, discriminación.

\section{The evolution of the constitutional right to survivor annuity by same-sex couples: a legal purview}

\section{Abstract}

In Colombia, the Constitutional Court has ruled repeatedly on the right to survivor annuity for same-sex couples, noting that the term survivor annuity is understood as:

A fundamental right of a certain, undeniable and inalienable nature due to its close association with values subject to protection, such as the right to life, social security, health and work, conditions that give it an inalienable, inherent and essential character given the helplessness of the beneficiary whose right should be recognized and remunerated. (T-173/1994, A. Martinez)

According to the above, this article aims to establish from a legal perspective whether the acquired right of survivor annuity between same-sex couples is being recognized. The methodology used is part of the historical-hermeneutic method proposed by Habermas, because with it one can understand the impact that the new possibility of "family" has had on our country and the way in which this new possibility of "family" comes with certain rights and certain obligations for same-sex partners. It also highlights the vulnerability to which these same-sex couples are permanently exposed. This paper adopts a theoretical and dogmatic method and studies the progress that the law has had on the protection of the right to survivor annuity for same-sex couples through the Colombian Constitutional Court's interpretation.

As a general conclusion, it appears that there is a problem of discrimination against same-sex couples in Colombia, which includes the violation of all kinds of rights and violates fundamental rights, especially the right to equality.

Keywords: survivor annuity, homosexual, law, equality, fundamental rights, Constitution, discrimination. 


\section{Evolução constitucional do direito à pensão de sobrevivente de casais do mesmo sexo: âmbito jurisprudencial}

\section{Resumo}

Na Colômbia, a Corte Constitucional tem se pronunciado em reiteradas ocasiões a respeito do direito à pensão de sobrevivente entre os casais do mesmo sexo, assinalando que se entende por pensão de sobrevivente:

Aquele direito fundamental de caráter certo, indiscutível e irrenunciável, por estar associado intimamente com valores sujeitos de tutela, como o direito à vida, à segurança social, à saúde e ao trabalho, condições estas que Ihe dão o caráter inalienável, inerente e essencial, dada a indefensibilidade do beneficiário respeito a quem deve reconhecer-Ihe e pagar-lhe seu direito. (T-173/1994, A. Martínez).

Conforme o anterior, este artigo pretende estabelecer se está se reconhecendo o direito adquirido de pensão de sobrevivente entre os casais do mesmo sexo, desde uma perspectiva jurisprudencial. A metodologia empregada parte do paradigma histórico-hermenêutico proposto por Habermas, já que com ele se pode entender o impacto que tem tido em nosso país a nova possibilidade de "família", com a qual se geram uns direitos e umas obrigações entre os participantes que seriam as pessoas do mesmo sexo, destacando a vulnerabilidade à que se expõem permanentemente.

O método adotado é o teórico-dogmático. Estuda-se o avanço que tem tido a jurisprudência na proteção ao direito de pensão de sobrevivente para os casais do mesmo sexo, mediante a interpretação que tem dado a Corte Constitucional colombiana.

Como conclusão geral, se evidencia que existe na Colômbia um problema de discriminação frente aos casais do mesmo sexo, que inclui a vulnerabilidade de direitos de todo tipo, e que transgrede os direitos fundamentais, especialmente $o$ direito à igualdade.

Palavras-chave: pensão de sobrevivente, homossexual, jurisprudência, igualdade, direitos fundamentais, Constituição, discriminação. 


\title{
Evolución constitucional del derecho a la pensión de sobreviviente de las parejas del mismo sexo: ámbito jurisprudencial*
}

\author{
Adriana María Buitrago Escobar ${ }^{* *}$ \\ $* * *$ \\ María Fernanda Suárez Trujillo \\ Yaniza Giraldo Restrepo ${ }^{* * * *}$
}

SUMARIO

Introducción - I. DERECHO FUNDAMENTAL DE PENSIÓN EN LAS PAREJAS DEL MISMO SEXO - A. Definición y tipos de pensión en el ordenamiento jurídico colombiano - B. Regímenes pensionales - C. Pensión de sobrevivientes - II. LA TEORÍA DE LA IGUALDAD COMO JUSTIFICANTE PARA LA PROTECCIÓN DE LA PENSIÓN DE SOBREVIVIENTES EN LAS PAREJAS DEL MISMO SEXO - III. LIINEA JURISPRUDENCIAL - IV. CONCLUSIONES - Referencias.

Cómo citar este artículo: Buitrago Escobar A. M., Suárez Trujillo, M. F. y Giraldo Restrepo, Y. (Diciembre, 2015). Evolución constitucional del derecho a la pensión de sobreviviente de las parejas del mismo sexo: ámbito jurisprudencial. Revista de Derecho Público, 35. Universidad de los Andes (Colombia).

** Doctora en Derecho y máster en Derecho con orientación investigadora por la Universidad de Alcalá de Henares (Madrid-España), abogada por la Universidad Santiago de Cali. Docente investigadora de tiempo completo de la Universidad de San Buenaventura, Cali; directora del Semillero de Investigación en Derecho Laboral y de la Seguridad Social LABYSS, adscrito a la línea de investigación avalada y financiada por la Universidad de San Buenaventura "Distinciones y conexiones entre los conceptos de seguridad social y derechos fundamentales". Coordinadora de la Especialización en Derecho Laboral y Seguridad Social, docente de Maestría en Derecho de la Universidad Santiago de Cali, docente de la Especialización en Derecho Laboral de la Universidad Libre de Cali. Correo: ambuitrago1@usbcali.edu.co

*** Estudiante de X semestre de pregrado en Derecho y Ciencias Políticas de la Universidad de San Buenaventura, Cali; miembro del Semillero de Investigación en Derecho Laboral y de la Seguridad Social LABYSS, adscrito a la línea de investigación avalada y financiada por la Universidad de San Buenaventura, "Distinciones y conexiones entre los conceptos de seguridad social y derechos fundamentales". Correo: mafer2425@hotmail.com

**** Doctora en Derecho y máster en Derecho Público por la Universidad Carlos III de Madrid (Madrid-España), máster en Derecho Internacional por la Universidad Complutense de Madrid (Madrid-España). Abogada por la Universidad Libre de Cali. Docente investigadora de tiempo completo de la Universidad de San Buenaventura, Cali, adscrita a la línea de investigación avalada y financiada por la institución, "Distinciones y conexiones entre los conceptos de seguridad social y derechos fundamentales". Correo: ygiraldo1@usbcali.edu.co 


\section{Introducción}

En Colombia, el reconocimiento del derecho de pensión a las parejas homosexuales nace por vía jurisprudencial, lo cual quiere decir que es a través de las sentencias de la Corte Constitucional que se les otorga y garantiza. Esto evidencia que realmente no existe una ley que proteja sus derechos, los cuales se estarían dejando a la subjetividad del operador jurídico, en cuanto a decidir si se les reconocen o no.

Tal como lo establece la Constitución Política en sus artículos primero y decimotercero, en los cuales determina las libertades y garantías de los ciudadanos, no se estaría cumpliendo en sentido estricto la finalidad de la norma superior, dado que la vulneración de los derechos de estas parejas es permanente no solo en materia pensional, sino en otros derechos conexos.

Conforme lo señala la evolución normativa de los derechos de las personas homosexuales, se observa una desigualdad respecto de las parejas heterosexuales. Mientras las últimas son sujetos de derechos sin objeciones, las homosexuales requieren acudir a los estrados judiciales para ser reconocidas como sujetos de los mismos derechos, discriminación que obedece exclusivamente a la orientación sexual que se manifieste. Por lo tanto, este artículo pretende establecer desde una perspectiva jurisprudencial, si se está otorgando el reconocimiento al derecho adquirido de pensión a las parejas del mismo sexo.

Existen diversos planteamientos frente a la problemática planteada. Si se parte de la igualdad reconocida constitucionalmente, se puede afirmar que las parejas del mismo sexo han sido objeto de discriminación jurídica; y si se analiza desde el reconocimiento consagrado en la jurisprudencia, este tampoco es aplicado en la práctica, con lo cual no se cumple con la función garantista y proteccionista del ordenamiento jurídico colombiano.

Si bien es cierto que los derechos de las parejas homosexuales no se encuentran reconocidos de manera expresa en el ordenamiento jurídico colombiano, sí lo han sido mediante desarrollo jurisprudencial. En efecto, la Corte Constitucional en diferentes sentencias ha reconocido el derecho pensional al compañero(a) permanente del mismo sexo (C-336 de 2008, C. Vargas) y en la sentencia T-051 de 2010 equipara los requisitos de acceso a dicha prestación para las parejas del mismo sexo evidenciando una evolución jurisprudencial en la interpretación jurídica colombiana. Se llega a esta conclusión a través de la construcción y análisis de la línea jurisprudencial que aborda directamente la problemática desde la perspectiva del derecho a la igualdad.

La presente reflexión sobre el tema ha sido dividida en cuatro partes: la primera de ellas trata el tema del derecho fundamental de pensión en las parejas del mismo sexo, su definición y tipos pensionales, regímenes existentes en Colombia, con especial referencia a la pensión de sobreviviente por ser el eje central de este artículo, señalando su aplicabilidad en los dos regímenes pensionales contemplados en el ordenamiento jurídico colombiano. 
Posteriormente se aborda la teoría de la igualdad como sustento teórico justificante para la protección de la pensión de sobreviviente en las parejas del mismo sexo. En tercer lugar se construye una línea jurisprudencial frente a la evolución del derecho de pensión de las parejas del mismo sexo, enfatizando en el tipo de pensión que se estudia: la pensión de sobreviviente. Tal construcción analítica utiliza el método desarrollado por Diego López Medina para tal fin, y se toma como período de análisis los años 2010-2014. Finalmente, se establecen unas conclusiones como resultado de la línea jurisprudencial construida, contrastada con la teoría de la igualdad.

\section{DERECHO FUNDAMENTAL DE PENSIÓN EN LAS PAREJAS DEL MISMO SEXO}

El concepto clásico de pareja heterosexual ha evolucionado con el paso del tiempo en los sistemas jurídicos internacionales. Actualmente más de 39 países a nivel mundial pretenden fomentar la igualdad entre las parejas heterosexuales y las parejas del mismo sexo.

Rodríguez Vázquez (2008, págs. 914-915) señala que en países como España se modificó el Código Civil en 2005, en lo que respecta al derecho a contraer matrimonio de las parejas homosexuales, otorgando los mismos derechos y obligaciones que se derivan del vínculo legal en las parejas heterosexuales. Según cifras del Instituto de Estadística, para el 2006 en España se registraron 211.818 matrimonios mixtos (BOE, núm. 157, 2 de julio de 2005).
En Colombia, la unión marital de hecho de las parejas del mismo sexo se ha reconocido por vía jurisprudencial, mediante la sentencia C-075 de 2007 , en la cual se declara la discriminación legal contenida en la Ley 54 de 1990, modificada por la Ley 979 de 2005, entre parejas homosexuales y heterosexuales, sin que se argumente jurídicamente las razones de tal exclusión. Con este reconocimiento se inicia la lucha por parte de la comunidad LGBTI, para que las entidades gubernamentales y privadas apliquen la interpretación jurisprudencial emitida por el órgano de cierre.

A partir del pronunciamiento de la Corte Constitucional en la sentencia C-336 de 2008, se determina la inexequibilidad de la Ley 100 de 1993 en sus artículos 47 y 74, modificados por la Ley 79 de 2003, que limitaban los beneficios de la protección en materia de pensión de sobrevivientes a las parejas heterosexuales, estableciendo de nuevo discriminación en contra de las parejas del mismo sexo. Por este motivo, la Corte decide ampliar la protección otorgada a los compañeros y compañeras permanentes de las parejas homosexuales, porque:

\begin{abstract}
No existe un fundamento razonable y objetivo suficiente para explicar el trato desigual al que vienen siendo sometidas las personas que, en ejercicio de sus derechos al libre desarrollo de la personalidad y a la libertad de opción sexual, han decidido conformar una pareja con una persona de su mismo género. (CConst., C-336 de 2008, C. Vargas).
\end{abstract}

No obstante lo anterior, el sistema jurídico colombiano continúa carente de una legislación 
concreta que proteja los derechos y obligaciones de las parejas homosexuales, equiparándolas con las heterosexuales en todos los ámbitos del desarrollo humano.

\section{A. Definición y tipos de pensión en el ordenamiento jurídico colombiano}

En Colombia, el Sistema General de Pensiones ha evolucionado constantemente, no solo por la inclusión de las parejas del mismo sexo dentro del régimen, sino también por el cambio estructural que se ha dado paulatinamente. Es importante resaltar que la reforma estructural al Sistema Pensional no afecta el reconocimiento de derechos a las parejas del mismo sexo; por el contrario, estas tienen la posibilidad de escoger entre los dos modelos que ofrece el sistema, y optar autónomamente por el que consideren más rentable tanto para el aportante como para el beneficiario.

Para consolidar un concepto de pensión es necesario partir del análisis evolutivo que ha tenido el Régimen de Seguridad Social en Colombia. Con anterioridad a la entrada en vigencia de la Ley 100 de 1993, a través de la cual se modificó el Sistema General de la Seguridad Social, se aplicaba un modelo no integrado en el cual cada uno de los sistemas operaba completamente independiente, esto es, el de riesgos laborales, el de salud y el de pensión. En tal virtud, con la promulgación de la Ley 100 de 1993 se pretendieron tres objetivos principales, a saber: garantizar las prestaciones económicas y de salud definidas a quienes tienen capacidad económica suficiente tanto por existir una relación laboral como por devengar ingresos en forma independiente; garantizar la ampliación de la cobertura en dichas prestaciones a quienes carecen de capacidad económica y garantizar la protección de los servicios sociales complementarios.

Posteriormente se expidió la Ley 797 de 2003 que significó una importante reforma en materia pensional, y cuyo objetivo era transformar el fondo común del Instituto de Seguro Social y racionalizar los recursos, para cumplir en un futuro con la entrega de las mensualidades a los beneficiarios de este régimen.

Conforme lo plantea Arrieta Mendoza (2011, pág. 5), el legislador introdujo reformas como: aumento en la tasa de cotización o aporte de los afiliados; incremento en el tiempo mínimo de cotización requerido para acceder a la pensión de vejez; modificación en las tasas de reemplazo empleadas en la liquidación de las pensiones de vejez en el subsistema de prima media; reducción de la vigencia del período de transición establecido (se adelanta del $1^{\text {ro }}$ de enero de 2014 al $1^{\text {ro }}$ de agosto de 2010, excepto para trabajadores que hayan cotizado por lo menos 750 semanas a la aprobación de la reforma constitucional); fortalecimiento en las contribuciones al fondo de solidaridad pensional y reducción de las comisiones de administración de las administradoras de fondos de pensiones (AFP); y la obligatoriedad de afiliación de todos los trabajadores independientes.

Cabe resaltar que la Ley 797 de 2003 incluye en su contenido los principios consagrados por la Constitución Política, tales como la eficien- 
cia, universalidad y solidaridad, que ya se encontraban en la Ley 100 de 1993, pero con la pretensión de alcanzar el objetivo principal de solidaridad o viabilidad económica, así como la equidad frente al sistema, el cual debe velar por un trato igualitario y respetuoso para todos los afiliados, no solo por su calidad de personas sino por las expectativas legítimas de quienes se encuentran próximos a pensionarse.

En el mismo propósito, la Ley 797 de 2003 amplía la cobertura y contempla la prevención del riesgo que acarrea el desempleo, la adopción de medidas frente a lo que atañe a los regímenes pensionales exceptuados y especiales, como la pensión de las fuerzas militares, entre otros.

En principio, en Colombia operaba únicamente el régimen de prima media con prestación definida (RPMPD) para los empleados de las empresas del sector privado y aquellos que trabajaban por cuenta propia; a su vez existía un régimen especial dirigido a los empleados del sector público, el Ejército y la Policía. El RPM se encontraba bajo la administración del Instituto de Seguro Social y se caracterizaba por contar con un fondo común solidario que se abastecía de los dineros de cada uno de los aportantes, cuya cotización era mucho menor que el valor de la pensión (Hernández García , 2009, pág. 183). Algunos autores definen el RPM como un sistema pay as you go, consistente en que los aportes de los afiliados se dirigen a un fondo común desde donde son distribuidos a quienes se van pensionando durante el período en curso. Por su parte, Torres Galeano y Osorio Gómez (2011, pág. 59) señalan que el RPM cuenta con un fondo de reserva, creado desde hace treinta años, que garantiza el pago de las pensiones.

\section{B. Regímenes pensionales}

El modelo de seguridad social en materia pensional que se implementó en Colombia, inicialmente fue el de prima media o de reparto con beneficios, que consistía en que los aportantes en edad de trabajar realizaban sus contribuciones a un fondo común, del cual se pagaban las mesadas a las personas que se pensionaran. Si bien, en su momento, el RPM trajo beneficios a gran parte de la población y creó a su vez una base para el desarrollo del sistema pensional, después de veinte años de funcionamiento comenzó a mostrar señales de insostenibilidad financiera, baja cobertura e inequidad (Santa María, 2010, pág. 5).

Desde el año 1993 el país cuenta con un sistema general de pensiones dual, es decir, existen entidades tanto públicas como privadas que ofrecen el servicio de administrar los fondos pensionales de los afiliados. De un lado, se encuentra el RPM que se implementó en 1967, fecha en la cual los aportes pensionales para los empleados privados pasaron de ser voluntarios a tener carácter obligatorio y se delegó la administración de dichos fondos al Instituto Colombiano de Seguros Sociales (ISS) como entidad del Estado. Por otra parte, está el régimen de ahorro individual con solidaridad (RAIS), en el cual el aportante elige el fondo privado en el cual tendrá su cuenta de ahorro pensional, cuya administración estará a cargo de particulares, y sus requisitos de acceso varían frente al esta- 
blecido para el régimen de prima media (Santa María, 2010, pág. 7).

Posteriormente, el Sistema General de Pensiones ha venido atravesando una serie de dificultades en materia de sostenibilidad fiscal, concretamente en el régimen de prima media administrado por el Estado a través del Iss, hoy Colpensiones. En un esfuerzo por contrarrestar los efectos negativos de la administración de los fondos del sistema, se modifica el RPM y se diseña el RPMPD. Como resultado, se agruparon las cajas administradoras de fondos existentes y el RAIS, cuya administración quedó en cabeza de los fondos privados de pensiones. Esta reforma se hizo con el objeto de lograr equilibrio fiscal; aumentar la cobertura en lo relacionado con protección a la vejez, sobrevivencia e invalidez; fortalecer el sistema financiero y mejorar la eficiencia en el manejo de recursos.

Arias y Mendoza (2009, pág. 3) definen el RAIS como un sistema privado de capitalización individual, correspondiente a un régimen de contribución definida y de capitalización individual, donde los afiliados realizan su aporte de forma periódica a una cuenta personal y así acumulan los recursos que serán utilizados para el pago de sus pensiones al alcanzar la edad de retiro. Por lo anterior, el objetivo principal del RAIs es fomentar el ahorro "voluntario" del usuario para asegurar una estabilidad económica cuando sea el momento de su retiro por vejez, invalidez o muerte.

\section{Pensión de sobrevivientes}

Los antecedentes normativos de la pensión de sobrevivientes datan del siglo xx, tal como lo indica Rodríguez Lascarro (2013, pág. 139). Su finalidad era crear mecanismos legales de protección al grupo familiar que por el fallecimiento de la persona encargada de sus necesidades, queda totalmente desamparado.

Para llegar a lo que hoy se conoce como pensión de sobrevivientes, nuestro ordenamiento jurídico tuvo que experimentar una importante evolución. Partiendo de la promulgación de la Ley 29 de 1905 que reconoció la pensión a favor de las viudas de aquellos ciudadanos que prestaron sus servicios al Ejército, cuatro décadas después se emite la Ley 90 de 1946 creativa del iss y se establece el seguro social obligatorio de los trabajadores, concediéndoles la protección por muerte, y en consecuencia la pensión de sobrevivientes que por esa época se conocía como pensión de viudedad o pensión de orfandad, dependiendo de la calidad del beneficiario. Pero es a partir de la Ley 33 de 1973 que aparece el concepto tácito de sustitución pensional de manera vitalicia.

Al respecto, el Consejo de Estado señala que la pensión sustituta de manera vitalicia es un mecanismo de protección a los familiares del trabajador pensionado, que ante su deceso puedan quedar desamparados en razón de que ellos dependen económicamente del producto de su actividad laboral, lo que se constituye en protección directa de la familia, cualquiera sea su origen o fuente de conformación: jurídica o 
natural, heterosexual u homosexual (Contencioso Administrativa, 20 sep. 2007, J. Lemos).

Posteriormente, la Ley 44 de 1980 modificada por la Ley 1204 de 2008, dispuso en el artículo $1^{\circ}$ : "el pensionado al momento de notificarse del acto jurídico que le reconoce su pensión, podrá solicitar por escrito, que en caso de su fallecimiento, la pensión le sea sustituida de manera provisional a quienes él señale como sus beneficiarios". Sin embargo, con anterioridad, el Decreto 758 de 1990 había establecido como requisitos de acceso al derecho de pensión de sobrevivientes, que el cotizante tuviera como mínimo 150 semanas cotizadas; que la muerte no se hubiera producido por una causa profesional; como beneficiario de forma vitalicia al cónyuge supérstite, y a falta de este el compañero permanente, que debía ser soltero y haber convivido con el afiliado como mínimo los tres años inmediatamente anteriores al fallecimiento de este.

Lo anterior representa una garantía constitucional, además del cumplimiento de los objetivos de la seguridad social que consisten en velar porque las personas que se vean en la imposibilidad temporal o permanente de producir su propio sustento, o que por haber perdido a la persona que sufragaba los gastos para el sostenimiento del núcleo familiar puedan gozar de un ingreso económico que les permita mantener su calidad de vida, en condiciones dignas (Rodríguez Lascarro, 2013, pág. 142).

En el mismo sentido, la Corte Constitucional señala que la pensión de sobreviviente que la
Constitución Política estableció puede llegar a constituirse en derecho fundamental, por conexidad, en caso de que de ella dependa la garantía del mínimo vital del accionante. Es por ello que sin importar si la pareja es heterosexual u homosexual, a dicha pensión debe reconocérsele y brindársele las garantías necesarias para su disfrute (sentencia T-049 de 2002, M. Monroy).

A su vez, entidades como la Organización Internacional del Trabajo (oıт) definen la pensión de sobreviviente como aquella protección económica para los miembros de un núcleo familiar en caso de fallecimiento del afiliado o pensionado, recordando que debe existir siempre una dependencia económica por parte del beneficiario de dicha pensión; si no se demuestra esta dependencia no habrá obligación de otorgarla.

Ahora bien, en el marco del RPM la pensión de sobrevivientes está regulada en el capítulo IV del título II de la Ley 100 de 1993, artículos 46 al 49 , Ios cuales posteriormente fueron modificados por la Ley 797 de 2003 planteando, grosso modo, los requisitos necesarios para su obtención, los beneficiarios de esta, el monto y la respectiva indemnización sustitutiva.

Dentro de este régimen, la pensión de sobrevivientes pretende la protección para los descendientes del afiliado, previo el cumplimiento de unos requisitos estipulados por la ley, que son: pertenecer al grupo familiar del pensionado fallecido, que el pensionado fallecido hubiere cotizado cincuenta (50) semanas dentro de los tres (3) últimos años anteriores al fallecimiento 
y acreditar que la muerte fue causada por enfermedad o por accidente. Sus beneficiarios de forma vitalicia serán el cónyuge o la compañera permanente o supérstite.

En la sentencia C-336 de 2008, la Corte incluyó dentro de los beneficiarios de la pensión de sobrevivientes a las parejas permanentes del mismo sexo, siempre y cuando logren acreditar su condición a través de declaración ante notario y tengan o sean mayores de 30 años. Así mismo serán beneficiarios de manera temporal de la pensión de sobrevivientes: i) el compañero(a) permanente que sea menor de 30 años y no haya procreado hijos con el causante, para este tipo de beneficiarios la pensión tendrá un tiempo límite de 20 años; ii) los hijos menores de 18 años y hasta los 25 años que se encuentren incapacitados para trabajar por razones de estudio o por razón de algún tipo de invalidez; iii) a falta de los anteriores, los padres podrán beneficiarse de la pensión de sobrevivientes siempre y cuando dependieran económicamente del faltante; y iv) a falta de estos los hermanos inválidos que demuestren dependencia económica del causante.

\section{LA TEORÍA DE LA IGUALDAD COMO JUSTIFICANTE PARA LA PROTECCIÓN DE LA PENSIÓN DE SOBREVIVIENTES EN LAS PAREJAS DEL MISMO SEXO}

La Corte Constitucional, como entidad estatal, ha sido el órgano que mayoritariamente ha trabajado por la protección y reconocimiento de las parejas del mismo sexo. En sus sentencias ha utilizado como sustento teórico jurídico la igualdad en tanto método de inclusión, en busca de protección a aquellas poblaciones o sectores menos favorecidos que cuentan con los mismos derechos y deberes, sin distinción alguna (Hierro, 2003, pág. 454).

En este sentido, la igualdad tiene una conexión con la justicia desde Aristóteles, y con el desarrollo histórico se ha fortalecido tal conexión. Al respecto Hierro (2003, pág. 454) manifiesta que lo que realmente separa las visiones desde Aristóteles y los siglos posteriores hasta finales del xvIIII, no es la configuración de la justicia como igualdad sino la asunción de que todos los hombres somos iguales. Así las cosas, es necesario señalar que la igualdad no se refiere a uniformidad, al menos no en el tema objeto de estudio; por el contrario, alude a un trato igual en situaciones diferentes, en otras palabras, este principio propende por el respeto continuo y deliberado de las diferencias entre congéneres, en razón de la igualdad que se proclama en la Constitución y la ley, es decir, igualdad como sinónimo de no discriminación por ninguna razón. En ocasiones, situaciones diversas deben recibir un tratamiento jurídico distinto, y esto no significa discriminación sino sencillamente reconocimiento de la variedad de casos que pueden exigir -en virtud de la misma justicia- soluciones diferentes. Se entiende por discriminación la exclusión, por principio, que se hace para que un sujeto determinado no pueda gozar de un trato específico en iguales circunstancias.

La teoría de la igualdad reúne las condiciones para soportar la relación de un concepto abs- 
tracto sobre derechos sociales, y además tiene la capacidad de determinar por qué y desde dónde pueden los grupos sociales o las personas ser tratados iguales o desiguales. Las condiciones, interrelaciones, dicotomías en los conceptos representan la mejor forma como estos pueden determinar su aplicación al caso concreto y sus variaciones y utopías. Es en el contexto de la teoría de la igualdad desde donde puede representarse mejor una estructura conceptual, desde donde puede analizarse de forma concreta cómo los derechos sociales tienen límites y condiciones de aplicación y relación con otros conceptos como la moral.

La teoría de la igualdad guarda una estricta relación con el concepto de moral en el sentido, por ejemplo, de Rawls, donde se predican ciertas condiciones que deben tener los participantes en un discurso: ser agentes morales. Los débiles conceptos que hasta hoy existen sobre el tema no explican cómo los derechos sociales pueden entenderse en el pasado, en el presente y en el futuro. Entre estos derechos sociales es claro que el derecho a la seguridad social representa una forma de bienestar particular (Rawls, 1971).

En esta misma línea, la igualdad se puede ver desde dos perspectivas. La primera, en un sentido tenue, hace referencia al hecho de que dos casos análogos son tratados de manera diferente, y no parece haber razones suficientes para justificar un trato diferenciador por parte del sistema jurídico. Esta igualdad tenue se estaría violando cuando de manera injustificada se utiliza la orientación sexual para la distribu- ción de derechos y obligaciones básicas de los ciudadanos.

La segunda, referente a la igualdad fuerte, consiste en una diferenciación jurídica trascendental para dos tipos de uniones válidamente reconocidos, creando con ello un reconocimiento y a su vez una exclusión. Este tipo de igualdad se trasgrede cuando se realizan distinciones infundadas entre dos tipos de sujetos, los miembros de las parejas del mismo sexo y las parejas heterosexuales, negando de esta manera el reconocimiento de sus derechos (Bonilla, 2010, pág. 196).

Por su parte, Bernal Pulido (2002, pág. 51) define el derecho a la igualdad como aquel derecho que se le atribuye al individuo para exigir al Estado el cumplimiento de mandatos que se derivan del principio de igualdad. Pero resalta que se debe tener presente que muchas veces se habla de derecho y otras de principio, es decir, la igualdad en la ley y la igualdad ante la ley. EI primero se refiere al derecho fundamental, esto es, a la eficacia vinculante frente al legislador, y el segundo a la eficacia vinculante de los mandatos de la igualdad en la aplicación administrativa y jurisdiccional de la ley, en las relaciones entre particulares.

En suma, en las diferentes conceptualizaciones e interpretaciones de la teoría de la igualdad, la Corte Constitucional en sus sentencias de constitucionalidad o de tutela cree consecuente su utilización, basando sus argumentos en que no existe diferenciación justificada entre las parejas heterosexuales y las parejas del mismo 
sexo, tan relevante como para que esta institución desconozca sus derechos al tratar el tema de la pensión de sobrevivientes. De modo que, siempre y cuando las parejas del mismo sexo cumplan con los requisitos exigidos por la ley, se les debe reconocer de manera automática la pensión sin necesidad de la imposición de acciones legales.

\section{LIINEA JURISPRUDENCIAL}

Como ya se ha planteado en el desarrollo del presente artículo, el reconocimiento de los derechos de las parejas del mismo sexo ha sido por vía jurisprudencial, ya que actualmente se carece de una legislación concreta sobre el tema.

Para analizar la evolución del derecho de pensión de las parejas del mismo sexo es pertinente hacer un breve recorrido por las diferentes sentencias que llevaron a que dicho reconocimiento fuera posible, al tenor de lo establecido en los artículos 13 y 16 de la Constitución Política, así como la revisión de su aplicación por parte de la Corte Constitucional bajo la óptica de la teoría de la igualdad planteada con anterioridad. Esto, a fin de determinar el tratamiento que vía jurisprudencial ha mantenido la Corte Constitucional, y que ha sido determinante en el cese de la vulneración de los derechos de las parejas del mismo sexo en el ordenamiento jurídico colombiano.

Inicialmente la Corte constitucional, en sentencia T-349 de 2006, niega al tutelante el reconocimiento de la pensión de sobrevivientes argumentando que dicha prestación iba dirigida a la familia, por lo cual es deber del legislador ampliar el concepto de familia de modo que incluya la conformada por parejas del mismo sexo, como una forma adicional de constituir el núcleo familiar.

Posteriormente, la Corte Constitucional en sentencia C-075 de 2007 decide en sentido contrario, al reconocer la existencia jurídica de las parejas del mismo sexo y otorgarles la posibilidad de conformar un patrimonio único.

Con este importante avance se consolida jurídicamente el reconocimiento del derecho a conformar una sociedad patrimonial entre la pareja del mismo sexo, en igualdad de condiciones legales que las establecidas para las parejas heterosexuales por el vínculo del matrimonio. Así mismo, a través de la sentencia C-811 de 2007 se reconoce la afiliación al Sistema de Seguridad Social como beneficiario.

Pero es mediante la sentencia C-336 de 2008 que se reconoce el derecho que tiene la pareja supérstite de recibir pensión de sobrevivientes, en virtud del derecho a la igualdad constitucionalmente reconocido y protegido, ya que tanto las parejas heterosexuales como las homosexuales hacen vida en común y, por ende, no pueden ser objeto de tales vulneraciones. Sin embargo, al igual que las parejas heterosexuales se ven en la obligación de cumplir con los requisitos preestablecidos para la obtención de la pensión de sobrevivientes.

Al construir la línea jurisprudencial sobre la pensión de sobrevivientes en las parejas del mis- 
mo sexo, se toman como referencia temporal los pronunciamientos de la Corte Constitucional colombiana entre los años 2010 -2014. En ese orden de ideas se determina que la sentencia arquimédica es la C-336 de 2008, dada su importancia frente al contenido prestacional en las parejas del mismo sexo. La demanda de inconstitucionalidad se profiere en contra de los artículos 47 y 74 de la Ley 100 de 1993, modificados posteriormente por el artículo 13 de la Ley 797 de 2003, que desde el punto de vista de los accionantes vulneran el artículo 13 de la Constitución Política, ya que excluyen a las parejas del mismo sexo de la protección de seguridad social que es ofrecida a las parejas heterosexuales. Legalmente, las parejas heterosexuales pueden ser beneficiarias de la pensión de sobrevivientes sin ningún problema, pero cuando es un compañero permanente del mismo sexo quien acude a reclamar su derecho, se encuentra con una serie de dificultades de orden administrativo derivadas de la falta de legislación concreta para el caso.

Por lo anterior, la Corte declara la exequibilidad condicional, ya que se debe entender que las parejas del mismo sexo también podrán ostentar la calidad de beneficiarios de la pensión de sobrevivientes sin ningún tipo de dificultades.

Del análisis citacional de la sentencia arquimédica C-336 de 2008 se pudo observar que la Corte hace un recuento de los derechos que le han sido reconocidos a las parejas del mismo sexo, donde menciona sentencias como la C-075/07 y C-811/07, lo cual permitió formar el primer nivel del nicho citacional; el segundo nivel se formó con las sentencias C-098/96, SU623/01, C-075/07 y C-814/01.

A continuación se pasa a realizar el análisis de las sentencias que conforman el nicho citacional de la sentencia C-336 de 2008, para determinar si el derecho adquirido de pensión de sobrevivientes de las parejas del mismo sexo está siendo reconocido. Antes, se realizará una pequeña descripción de cada una de las sentencias utilizadas en el nicho citacional.

En la sentencia C-098 de 1996 la Corte Constitucional revisa la constitucionalidad de la Ley 54 de 1990, cuyo problema radica en la vulneración de los derechos fundamentales y los conexos a ellos de las parejas del mismo sexo, dado que no se les reconocen los mismos derechos con que cuentan las parejas heterosexuales, solo por su condición de homosexuales.

Dado que las parejas homosexuales no son reconocidas como unión marital de hecho, no cuentan con un régimen patrimonial entre compañeros permanentes. El demandante alega que al igual que una pareja heterosexual, las parejas homosexuales se unen con la intención de conformar una comunidad de vida, razón que para la Corte no es suficiente, ya que en este momento el concepto de familia es excluyente. Para la Corte, una unión homosexual no es lo mismo que una unión heterosexual, puesto que su composición obviamente es diferente; por esta razón, una unión homosexual no puede ser considerada como familia y por lo mismo no será tomada en cuenta por la ley. 
Lo anterior no sería contrario a la ley, ya que el objeto de su creación tuvo como intención principal tutelar la familia natural, y tal como lo define la sentencia C-239 de 1994:

Para todos los efectos civiles, se denomina unión marital de hecho, la formada entre un hombre y una mujer, que sin estar casados, hacen una comunidad de vida permanente y singular. Igualmente, y para todos los efectos civiles, se denominan compañero y compañera permanente, al hombre y la mujer que forman parte de la unión marital de hecho.

Con base en lo anterior la Corte Constitucional declaró la exequibilidad de los artículos demandados de la Ley 54 de 1990.

La sentencia C-075 de 2007 es una sentencia determinante, dada la postura flexible y abierta que toma la Corte; también es considerada una sentencia hito en la jurisprudencia colombiana, por tratar temas vitales para las parejas del mismo sexo, como son los derechos patrimoniales, la protección del régimen patrimonial de los compañeros permanentes y la necesidad de incluir a las parejas del mismo sexo en la normatividad, toda vez que las leyes colombianas solo hacen referencia a las parejas heterosexuales. Tal postura se basa en la teoría de la igualdad, misma que da pie para recordarle a la sociedad que a través de diferentes fallos el mencionado órgano de cierre en materia constitucional proscribió cualquier forma de discriminación existente, y si la hubiese, se tendría como inconstitucional.

Pero más allá de lo que ha dictado la Corte, este grupo minoritario sigue siendo víctima de discri- minación y esta vez por parte del ordenamiento jurídico, ya que carece de reconocimiento por parte de este. Frente a esto la Corte concluye:

La falta de reconocimiento jurídico de la realidad conformada por las parejas homosexuales, es un atentado contra la dignidad de sus integrantes porque lesiona su autonomía y capacidad de autodeterminación al impedir que su decisión de conformar un proyecto de vida en común produzca efectos jurídicos patrimoniales.

Con la decisión tomada por la Corte el concepto de familia tradicionalmente conocido da paso a un nuevo modelo, en el cual las uniones homosexuales son equiparadas a las uniones tradicionales, y gozan de protección constitucional cuya finalidad es la defensa de los posibles abusos que se puedan presentar.

En la sentencia C-811 de 2007 la Corte Constitucional analiza si el artículo 163 de la Ley 100 de 1993, atinente a la cobertura familiar, es inconstitucional al vulnerar los derechos de las parejas homosexuales, toda vez que el concepto de familia que maneja el Estado es muy limitado, dejando por fuera las parejas homosexuales, generando discriminación y vulnerando derechos constitucionalmente establecidos, entre ellos el derecho a la igualdad y dignidad humana. En consecuencia, declara la exequibilidad toda vez que el sistema de seguridad social en el régimen contributivo admite la cobertura de las parejas del mismo sexo, con la respectiva comprobación de su calidad como pareja permanente, tal como lo consagra la sentencia C-521 de 2007. Esto con la misma rectitud se le exige a las parejas heterosexuales, es decir, que aquellas parejas que 
realmente no conforman una familia no puedan defraudar al Estado reclamando unos beneficios que no les corresponden.

En la sentencia unificadora SU-623 de 2001, la Corte Constitucional revisa el fallo adoptado por el Juez Noveno Civil Municipal de Medellín dentro de la acción de tutela instaurada contra Comfenalco E. P. S., por cuanto el accionante considera que se le vulnera el derecho a la salud y la seguridad social por su condición de homosexual, ya que no le fue permitido acceder al régimen contributivo de la seguridad social como beneficiario de su pareja, aun anexando y cumpliendo todos los requisitos exigidos por la ley.

La argumentación del juez de tutela para negar el amparo fue:

Es erróneo sostener que la relación que tiene el accionante con su pareja del mismo sexo, se asimile a lo más mínimo (sic), a compañeros permanentes ya que la sociedad, ni la ley ni la jurisprudencia de nuestro país a la fecha los ha asimilado a esa categoría, simplemente es una forma de ser y de actuar, pero en momento alguno, se asimila a la categoría que le quiere imprimir el tutelante. (...) Por lo tanto, no puede haber el establecimiento de los mismos derechos y obligaciones de una relación irregular, a una regulada por la ley y que a la fecha no ha sido reglamentada.

Por lo anterior, la Corte consideró pertinente proferir un pronunciamiento ambiguo, que en principio no incluye a las parejas homosexuales de los afiliados en calidad de beneficiarios del régimen contributivo en seguridad social, lo que comporta un trato discriminatorio puesto que el legislador tomó la decisión de ampliar la cobertura a las parejas homosexuales, para después argumentar que la no inclusión de este tipo de grupos marginados no necesariamente genera una vulneración al derecho de igualdad, ya que esta situación no deriva en una obligación a cargo del Estado de compensar esas violaciones.

Cabe resaltar que el magistrado Jaime Araújo Rentería en su salvamento de voto expone una tesis que ha sido reiterada en diferentes sentencias. En ella propone que la interpretación exegética que se le ha dado al artículo 42 de la Constitución Política no corresponde a lo que el legislador quiso dar a entender, ya que el término "o" permite que la formación de la familia sea "por la voluntad responsable de conformarla", sin necesidad de distinguir sexo, religión o raza. Lo anterior confiere una posibilidad para las parejas homosexuales, razón por la cual esta tesis es reiterada en distintas sentencias relacionadas con los derechos de estas.

En la sentencia C-814 de 2001, la Corte Constitucional resuelve una demanda de inconstitucionalidad contra el artículo 89 y 90 del Código del Menor, relativos a quiénes son aptos para adoptar. En dicha demanda el accionante expone que se está yendo en contra de las parejas homosexuales al no considerarlas como una opción para adoptar. La Corte inicia un análisis exhaustivo del artículo 42 de la Constitución Política en procura de argumentos sobre la protección de los menores y su derecho a tener una familia, y manifiesta que la moral de la que se habla en el artículo 89 del Código del Menor es 
necesaria, ya que garantiza los derechos y deberes tanto de los menores adoptados como de los padres adoptantes. De lo anterior se infiere que debe prevalecer el derecho a la educación moral del menor, frente al derecho de quien pretende adoptar, cumpliendo la norma con el mandato constitucional de la prevalencia del derecho de los niños.

La idoneidad moral que exige la ley no se refiere de manera explícita a aquellas personas que quieren adoptar y ostentan la calidad de homosexual, por el contrario, como se ha manifestado reiteradamente, se busca la protección del menor por encima de cualquier otro tipo de interés al igual que la familia. El modelo de familia estipulado por la Carta Política en su artículo 42 es la familia heterosexual y monogámica; en consecuencia, la Corte considera que la norma acusada es constitucional.

\section{CONCLUSIONES}

El sistema jurídico colombiano si bien ha avanzado en torno a la protección de los derechos de las parejas homosexuales, lo ha hecho por vía jurisprudencial mas no por vía legislativa.

Dentro de esos avances se encuentra el reconocimiento de la pensión de sobrevivientes a las parejas homosexuales en equivalencia a las heterosexuales, que ya ha generado un sinnúmero de procedimientos judiciales $\mathrm{y}$ ha incrementado la congestión judicial en el acceso a la justicia. Esta situación se evitaría si se legislara de manera concreta en la materia, para no dejar a la libre interpretación del operador jurídico el reconocimiento de tales derechos.

La Corte Constitucional ha establecido que la pensión de sobreviviente se constituye en un derecho fundamental, en el evento que de esta dependa la garantía del mínimo vital del accionante. Por tanto, no se debe hacer ninguna distinción entre la pareja heterosexual y homosexual, sino que este derecho se reconocerá sin discriminación alguna.

La Corte Constitucional ha interpretado este derecho desde la teoría de la igualdad, como mecanismo inclusivo cuyo objeto es proteger las personas o grupos minoritarios frente a la vulneración de sus derechos, estableciendo con ello una discriminación positiva al tener en cuenta que la noción de justicia está en conexión con la igualdad en el sentido de que todas las personas son iguales ante la ley. Así las cosas, las parejas del mismo sexo no pueden ser tratadas de manera diferente a las parejas heterosexuales, y no se les pueden otorgar derechos y obligaciones en virtud de su condición sexual.

La pensión de sobrevivientes cumple una función social: proteger económicamente a los miembros del núcleo familiar en caso de fallecimiento del afiliado o pensionado. De ahí el requisito fundamental de dependencia económica por parte del beneficiario de dicha pensión.

Colombia ha venido evolucionando en materia pensional, no a nivel legislativo sino jurisprudencial, por la posibilidad de interpretación de la Carta Política que consagra la igualdad de 
derechos entre sus asociados, sin distinción alguna. Y es por esta vía que se ha otorgado reconocimiento y protección a los derechos pensionales de las parejas homosexuales.

No obstante, es necesario implementar una legislación concreta que aborde la temática en todos sus ámbitos, a fin de que las parejas del mismo sexo no se vean obligadas acudir a los estrados judiciales para el reconocimiento de sus derechos. Se debe incluir dentro de una forma legal de constitución de familia la establecida por parejas del mismo sexo, con el objeto de que sean tratadas en condiciones de igualdad frente a las parejas heterosexuales.

\section{Referencias}

1. Arias, M. y Mendoza, J. C. (2009). Reporte de estabilidad financiera. Un modelo de simulación del régimen pensional de ahorro individual con solidaridad en Colombia. Bogotá: Banco de la República.

2. Arrieta Mendoza, C. I. (Septiembre de 2011). Las reformas del sistema pensional colombiano (Resumen ejecutivo). Bogotá: Friedrich Ebert Stiftung en Colombia -Fescol-.

3. Bernal Pulido, C. (2002). El juicio de la igualdad en la jurisprudencia de la Corte Constitucional colombiana. En J. Vega Gómez y E. Corzo Sosa (Coords.), Instrumentos de tutela y justicia constitucional. Memoria del VII Congreso Iberoamericano de Derecho Constitucional (págs. 51-74). México, D. F.: Universidad Nacional Autónoma de México.
4. Ley 13 de 2005. Por la que se modifica el Código Civil en materia de derecho a contraer matrimonio. Boletín Oficial del Estado. BOE, núm. 157. Julio 2 de 2005 (Madrid, España).

5. Bonilla, D. (2010). Parejas del mismo sexo en Colombia: tres modelos para su reconocimiento jurídico y político. Anuario de Derechos Humanos, 183-200.

6. Corte Constitucional de Colombia. Sentencia T-173 de 1994 (M. P.: Alejandro Martínez Caballero: abril 11 de 1994).

7. Corte Constitucional de Colombia. Sentencia C-239 de 1994. Expediente D-445 (M. P.: Jorge Arango Mejía: mayo 19 de 1994).

8. Corte Constitucional de Colombia. Sentencia C-098 de 1996. Expediente D-911 (M. P.: Eduardo Cifuentes Muñoz: marzo 7 de 1996).

9. Corte Constitucional de Colombia. Sentencia SU-623 de 2001. Expediente T-361534 (M. P.: Rodrigo Escobar Gil: junio 14 de 2001).

10. Corte Constitucional de Colombia. Sentencia C-814 de 2001. Expediente D-3378 (M. P.: Marco Gerardo Monroy Cabra: agosto 2 de 2001).

11. Corte Constitucional de Colombia. Sentencia T-349 de 2006 (M. P.: Rodrigo Escobar Gil: mayo 5 de 2006). 
12. Corte Constitucional de Colombia. Sentencia C-075 de 2007. Expediente D-6362 (M. P.: Rodrigo Escobar Gil: febrero 7 de 2007).

13. Corte Constitucional de Colombia. Sentencia C-811 de 2007. Expediente D-6749 (M. P.: Marco Gerardo Monroy Cabra: octubre 3 de 2007).

14. Corte Constitucional de Colombia. Sentencia C-521 de 2007. Expediente D-6580 (M. P.: Clara Inés Vargas Hernández: julio 11 de 2007).

15. Corte Constitucional de Colombia. Sentencia C-336 de 2008. Expediente D-6947. (M. P.: Clara Inés Vargas Hernández: abril 16 de 2008).

16. Corte Constitucional de Colombia. Sentencia T-051 de 2010. Expediente T-2.292.035, T-2.299.859, T-2.386.935 (M. P.: Mauricio González Cuervo: febrero 2 de 2010).

17. Consejo de Estado. Sala de lo Contencioso Administrativo, Sección Segunda, Subsección B, Rad. 76001-23-31-000-199901453-014 (C. P.: Jesús María Lemos Bustamante: septiembre 20 de 2007).

18. Hernández García, C. A. (2009). Efectos del sistema multifondos en el régimen de ahorro individual en Colombia. Revista de Economía del Rosario, 12(2), 183.

19. Hierro, L. L. (2003). Igualdad, generalidad, razonabilidad y crisis de la Ley. Doxa. Cuadernos de Filosofía del Derecho, (26).
20. Rawls, J. (1971). Teoría de la justicia. (M. D. González, Trad.) México, D. F.: Fondo de Cultura Económica.

21. Rodríguez Lascarro, L. M. (2013). Distribución de la pensión de sobreviviente en los nuevos modelos de familia en Colombia: cónyuge y compañero(a) permanente. Justicia, (24), 136-145.

22. Rodríguez Vázquez, M. A. (2008). Los matrimonios entre personas del mismo sexo en el derecho internacional privado español. Boletín Mexicano de Derecho Comparado, (122).

23. Santa María, M. S. (Abril 12 de 2010). El sistema pensional en Colombia: retos y alternativas para aumentar la cobertura. Obtenido de repository.fedesarrollo.org: http:// www.repository.fedesarrollo.org.co/bitstream/11445/351/1/El-sistema-pensionalen-Colombia_Retos-y-alternativas-para-aumentar-la-cobertura-12-de-abril-2011.pdf

24. Torres Galeano, D. y Osorio Gómez, M. (Marzo de 2011). Inequidad en el régimen pensional colombiano. Obtenido de ridum.umanizales: http://ridum.umanizales.edu.co:8080/xmlui/bitstream/ handle/6789/116/140_344.02_TG140. pdf?sequence $=1$ 